\title{
Visually Induced Dizziness in Children and Validation of the Pediatric Visually Induced Dizziness Questionnaire
}

\begin{abstract}
Marousa Pavlou ${ }^{1 *}$, Susan L. Whitney², Abdulaziz A. Alkathiry 2,3 Marian Huett ${ }^{4}$, Linda M. Luxon ${ }^{5}$, Ewa Raglan ${ }^{6}$, Emma L. Godfrey ${ }^{7}$ and Doris-Eva Bamiou ${ }^{5,6,8}$

${ }^{1}$ Centre of Human and Aerospace Physiological Sciences, King's College London, London, United Kingdom, ${ }^{2}$ Physical Therapy, School of Health and Rehabilitation Sciences, University of Pittsburgh, Pittsburgh, PA, United States, ${ }^{3}$ Physical Therapy, College of Applied Medical Sciences Majmaah University, Majmaah, Saudi Arabia, ${ }^{4}$ Department of Physiology, King's College London, London, United Kingdom, ${ }^{5}$ Department of Audiology, Royal National Throat, Nose and Ear Hospital, University College London NHS Hospital Trust, London, United Kingdom, ${ }^{6}$ Audiological Medicine Department, Great Ormond Street Hospital for Children, London, United Kingdom, ' Division of Health and Social Care, King's College London, London, United Kingdom, ${ }^{8}$ University College London Ear Institute, London, United Kingdom
\end{abstract}

Aims: To develop and validate the Pediatric Visually Induced Dizziness Questionnaire (PVID) and quantify the presence and severity of visually induced dizziness (ViD), i.e., symptoms induced by visual motion stimuli including crowds and scrolling computer screens in children.

Methods: 169 healthy (female $n=89$; recruited from mainstream schools, London, UK) and 114 children with a primary migraine, concussion, or vestibular disorder diagnosis (female $n=62$ ), aged 6-17 years, were included. Children with primary migraine were recruited from mainstream schools while children with concussion or vestibular disorder were recruited from tertiary balance centers in London, UK, and Pittsburgh, PA, USA. Children completed the PVID, which assesses the frequency of dizziness and unsteadiness experienced in specific environmental situations, and Strength and Difficulties Questionnaire (SDQ), a brief behavioral screening instrument.

Results: The PVID showed high internal consistency (11 items; $\alpha=0.90)$. A significant between-group difference was noted with higher (i.e., worse) PVID scores for patients vs. healthy participants $(U=2,436.5, z=-10.719, p<0.001)$; a significant difference was noted between individual patient groups $\left[\chi^{2}(2)=11.014, p=0.004\right]$ but post hoc analysis showed no significant pairwise comparisons. The optimal cut-off score for discriminating between individuals with and without abnormal ViD levels was 0.45 out of 3 (sensitivity 83\%, specificity $75 \%$ ). Self-rated emotional $(U=2,730.0, z=-6.169)$ and hyperactivity $(U=3,445.0, z=-4.506) S D Q$ subscale as well as informant $(U=188.5$, $z=-3.916)$ and self-rated $(U=3,178.5, z=-5.083)$ total scores were significantly worse for patients compared to healthy participants $(p<0.001)$.

Conclusion: $\mathrm{ViD}$ is common in children with a primary concussion, migraine, or vestibular diagnosis. The PVID is a valid measure for identifying the presence of $\mathrm{ViD}$ in children and should be used to identify and quantify these symptoms, which require specific management incorporating exposure to optokinetic stimuli. 


\section{INTRODUCTION}

Vertigo and dizziness are common but often ignored (1) symptoms in children, despite their adverse effects on psychological wellbeing, educational achievement, participation in school and leisure activity, and quality of life (QOL) (2-6). In children with concussion, dizziness at the time of injury is the strongest predictor for prolonged recovery (7). It is, therefore, imperative to identify symptoms early to make a correct diagnosis and instigate appropriate management, thus helping to avoid chronic illness (4). The most common causes of childhood vertigo and dizziness are migraine and migraine variants including vestibular migraine, peripheral vestibular syndromes, and head trauma $(5,8,9)$. However, diagnosing the cause of and managing dizziness in children is often delayed or missed due to factors including a lack of awareness about the presence of these symptoms in children, knowledge on how to elicit these when taking a history by pediatric health-care providers $(6,10)$, and the fact that children are often unable to describe their symptoms $(8,11,12)$. Questionnaires have recently been developed to address this clinical need by specifically helping children describe their dizziness (13) and its perceived impact (14) in the background of studies describing the clinical and diagnostic features of common dizziness and vertigo causes in children $(9,10,15)$. Besides establishing the correct diagnosis, an important prerequisite for successful treatment of dizziness (16) is correct identification of symptom triggers. A specific constellation of dizzy symptoms that may be highly prevalent in childhood and responsive to treatment is visually induced dizziness (ViD).

Visually induced dizziness is the term used to define dizziness and/or unsteadiness symptoms triggered by a complex, distorted, large field/moving visual stimulus including the relative motion of the visual surround associated with body movement (17), due to an over-reliance on visual cues for perception and postural responses (i.e., visually dependent) (18). It is a frequent symptom associated with high disability levels, prolonged illness, and poorer clinical outcome in adults with vestibular dysfunction (19) including vestibular migraine (20). Children may be more susceptible to $\mathrm{ViD}$ than adults, as they rely more on visual cues for spatial orientation and their ability to integrate multisensory input to resolve sensory conflicting situations that may provoke dizziness and imbalance is not fully mature until adolescence (21-23).

Visually induced dizziness responds well to rehabilitation incorporating structured exposure to optokinetic stimulation $(24,25)$ and is, therefore, important to identify. Currently, there is no systematic study of ViD in childhood. This may be due to poor appreciation of $\mathrm{ViD}$ outside the vestibular community (17), the absence of asking children about symptom triggers (15), and lack of a validated tool that will identify and quantify $\mathrm{ViD}$ in children.

Abbreviations: PVID, pediatric visually induced dizziness questionnaire; ViD, visually induced dizziness; QOL, quality of life; GOSH, Great Ormond Street Hospital; UPMC, University of Pittsburgh Medical Center; SDQ, strength and difficulties questionnaire; PVSQ, pediatric vestibular symptom questionnaire; PAF, principal axis factoring; ROC, receiver operating curves; PPPD, persistent posturalperceptual dizziness; CSD, chronic subjective dizziness; SD, standard deviation.
This study aimed to develop and validate the Pediatric Visually Induced Dizziness Questionnaire (PVID), to identify and quantify subjective ViD in children aged 6-17 years. Secondary study aims were to investigate ViD symptom severity in children with migraine, concussion, and/or vestibular disorders and to investigate the relationship between $\mathrm{ViD}$ and behaviors indicative of psychological problems in these children vs. healthy controls.

\section{MATERIALS AND METHODS}

\section{PVID Design and Validation}

The PVID design and validation $(26,27)$ included three main phases: (i) expert panel review of initial PVID items; (ii) pilot study to assess validity and reliability of the PVID questionnaire; and (iii) main validation study and normative data collection.

\section{Expert Panel Review}

Three consultant pediatric audio-vestibular physicians, two physical therapists, and a psychologist constructed and selected questionnaire items from symptoms recorded in clinic reports for children diagnosed with a vestibular disorder at the Audiological Medicine Department, Great Ormond Street Hospital (GOSH), London, UK and the validated Situational Characteristic Questionnaire (SCQ) $(18,28)$. The SCQ measures the frequency of symptom provocation or exacerbation in environments with visual-vestibular conflict or intense visual motion (e.g., watching moving television scenes).

\section{Pilot Study}

The 11-item questionnaire was modified (wording alterations, bigger font size) after review for ease of completion and acceptability by 10 healthy children and 5 with a vestibular disorder aged 6-15 years. Each item was rated on a 0 (never) to 3 (most of the time) scale; a "don't know" category was also included. The total score ranged from 0 to 33 and was normalized using the equation: total score/(total question number - "don't know" replies) to yield a score of $0-3$ with higher scores indicating greater symptom severity. For the final questionnaire, see Table $\mathbf{1}$.

\section{Procedure}

The study comprised of completing the (a) PVID; (b) question set asking about clinically diagnosed migraines, frequent dizzy spells, severe stomach pain, vomiting, loss of consciousness, binocular vision or hearing difficulty, medication, and regular doctor visits (13); (c) Pediatric Vestibular Symptom Questionnaire (13) (PVSQ), which quantifies self-reported vestibular symptoms in children; and (d) Strengths and Difficulties Questionnaire (SDQ), a brief behavioral screening questionnaire for 4- to 17-year olds $(29,30)$. The SDQ informant (4-10 years) and self-report versions (11-17 years) both include five subscales: emotional, conduct, hyperactivity/inattention, peer relationship problems, and prosocial behavior. Subscale scores range between 0 and 10; total score is the sum of the first four scales (range 0-40). The English UK and US versions ${ }^{1}$ were used for participants in the United Kingdom and United States, respectively.

${ }^{1}$ www.sdqinfo.org 
TABLE 1 | The pediatric visually induced dizziness questionnaire.

The following questions ask about how often you feel dizziness and unsteadiness in different places and situations. Please circle the best answer for you.

How often in the past month have you felt the following?

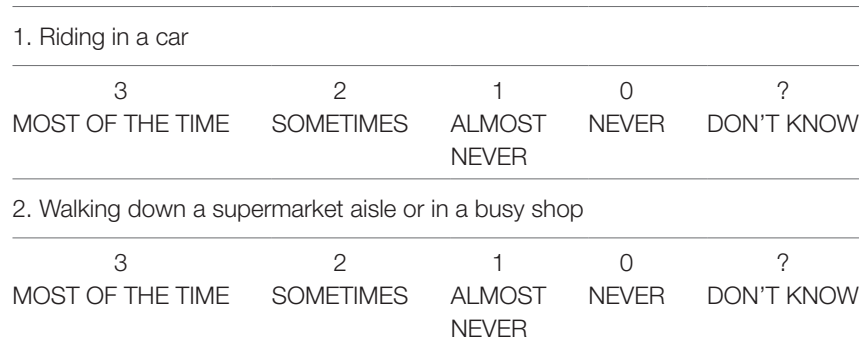

3. Standing in the middle of a wide open space (e.g., large football field or square)

\begin{tabular}{|c|c|c|c|c|}
\hline $\begin{array}{c}3 \\
\text { MOST OF THE TIME }\end{array}$ & $\stackrel{2}{2}$ SOMETIMES & $\begin{array}{l}1 \\
\text { ALMOST } \\
\text { NEVER }\end{array}$ & $\begin{array}{c}0 \\
\text { NEVER }\end{array}$ & $\begin{array}{c}? \\
\text { DON'T KNOW }\end{array}$ \\
\hline \multicolumn{5}{|c|}{ 4. Watching T.V. or at the cinema } \\
\hline $\begin{array}{c}3 \\
\text { MOST OF THE TIME }\end{array}$ & $\stackrel{2}{2}$ SOMETIMES & $\begin{array}{l}1 \\
\text { ALMOST } \\
\text { NEVER }\end{array}$ & $\begin{array}{c}0 \\
\text { NEVER }\end{array}$ & $\begin{array}{c}? \\
\text { DON'T KNOW }\end{array}$ \\
\hline \multicolumn{5}{|l|}{ 5. Riding on a bus } \\
\hline $\begin{array}{c}3 \\
\text { MOST OF THE TIME }\end{array}$ & $\stackrel{2}{2}$ SOMETIMES & $\begin{array}{l}1 \\
\text { ALMOST } \\
\text { NEVER }\end{array}$ & $\begin{array}{c}0 \\
\text { NEVER }\end{array}$ & $\begin{array}{c}? \\
\text { DON'T KNOW }\end{array}$ \\
\hline
\end{tabular}

6. Looking at striped or moving surface (e.g., curtains, flowing water)

\begin{tabular}{ccccc}
\hline 3 & 2 & 1 & 0 & $?$ \\
MOST OF THE TIME & SOMETIMES & $\begin{array}{c}\text { ALMOST } \\
\text { NEVER }\end{array}$ & NEVER & DON'T KNOW
\end{tabular}

7. Using the computer (e.g., emails, computer games)

\begin{tabular}{ccccc}
\hline 3 & 2 & 1 & 0 & $?$ \\
MOST OF THE TIME & SOMETIMES & ALMOST & NEVER & DON'T KNOW \\
& & NEVER & & \\
\hline
\end{tabular}

8. Watching moving traffic or trains (e.g., trying to cross the street or at the station)

\begin{tabular}{ccccc}
\hline 3 & 2 & 1 & 0 & $?$ \\
MOST OF THE TIME & SOMETIMES & $\begin{array}{c}\text { ALMOST } \\
\text { NEVER }\end{array}$ & NEVER & DON'T KNOW
\end{tabular}

9. Playing in the playground

\begin{tabular}{ccccc}
\hline 3 & 2 & 1 & 0 & $?$ \\
MOST OF THE TIME & SOMETIMES & $\begin{array}{l}\text { ALMOST } \\
\text { NEVER }\end{array}$ & NEVER & DON'T KNOW \\
\hline
\end{tabular}

10. Doing schoolwork

\begin{tabular}{ccccc}
\hline 3 & 2 & 1 & 0 & $?$ \\
MOST OF THE TIME & SOMETIMES & ALMOST & NEVER & DON'T KNOW \\
& & NEVER & & \\
\hline
\end{tabular}

11. Participating in sports (swimming, football, basketball, dancing)

\begin{tabular}{ccccc}
\hline 3 & 2 & 1 & 0 & $?$ \\
MOST OF THE TIME & SOMETIMES & $\begin{array}{l}\text { ALMOST } \\
\text { NEVER }\end{array}$ & NEVER & DON'T KNOW
\end{tabular}

Questionnaire copy not to scale.
Primary school children in years 1 and 2 completed the PVID and PVSQ together with a parent or guardian at home; those in year 3 and above or in secondary school completed them independently in the classroom under the standardized direction of a research team member. General questions were completed together with a parent or guardian at home. Children with a vestibular disorder or concussion and their parents completed the questionnaires during their clinic appointment.

\section{Participants}

Fifty-six children experiencing dizziness and/or unsteadiness due to a peripheral vestibular disorder $(n=14)$ or concussion $(n=42)$ were recruited from the Audiological Medicine Department, GOSH, and a tertiary balance center at the University of Pittsburgh Medical Center (UPMC), Pittsburgh, PA, USA, respectively. Inclusion criteria were (a) clinical diagnosis of concussion or other pathology resulting in vestibular dysfunction based on clinical history and clinical neuro-otological examination/test findings; (b) aged 6-17 years; (c) attend mainstream school. Exclusion criteria included children with (a) central nervous system involvement excluding migraine or concussion; (b) significant learning difficulties; or (c) orthopedic deficit affecting balance and gait. Diagnostic criteria are provided in Pavlou et al. (13).

Three hundred children aged 6-17 years were recruited from three primary and two secondary mainstream schools in the Greater London area. Of these,

- $n=58$ identified on the question set as diagnosed with migraine from their primary care physician comprised the migraine group.

- $n=169$ comprised the healthy control group.

- Children with a migraine diagnosis $(n=58)$, frequent dizzy spells $(n=27)$, vomiting, stomach pain, loss of consciousness, a neurological, psychological $(n=2)$ or orthopedic diagnosis, human immunodeficiency virus $(n=1)$, substance abuse history $(n=2)$, abnormal SDQ scores $(n=14)$ or an incomplete PVID $(n=1)$ or SDQ $(n=26)$ were excluded from the healthy group.

Written informed consent was obtained from all children and their parents before participating in the study in accordance with the Declaration of Helsinki. Ethical approval was obtained from the Institute of Child Health/GOSH Research Ethics Committee, London, UK and the institutional review board at the University of Pittsburgh, PA, USA.

\section{Data Analysis}

IBM SPSSv.23 (IBM Corp., Armonk, NY, USA) was used for statistical analysis. Data are presented as mean (standard deviation, SD). Reliability was tested using the Cronbach alpha score for total PVID items less one item at a time to examine whether reliability decreased when an item was excluded. Exploratory factor analysis with principal axis factoring (PAF) determined construct validity. The Kaiser criterion (eigenvalue $\geq 1$ ), a scree plot, and parallel analysis based on minimum rank factor analysis of polychoric correlations identified how many 
factors should be retained $(31,32)$. For the scree plot, factors lying before the point where eigenvalues began to drop were retained. The FACTOR PC program² (33) was used for parallel analysis.

Receiver operating curves (ROC) assessed discriminant validity to calculate the PVID's sensitivity and specificity in discriminating normal vs. abnormal ViD symptoms. MannWhitney tests determined between-group (healthy vs. patient) differences for age and questionnaire data. A Chi-Squared test determined between-group gender differences. Spearman's correlation investigated associations between PVID, SDQ, and PVSQ scores, age, gender, binocular vision, hearing difficulty, and migraine history; only significant correlations are reported. Significant results were assumed if $p \leq 0.01$.

Kruskal-Wallis test determined if differences existed in PVID and PVSQ scores between children with a primary migraine, concussion, or vestibular diagnosis. Pairwise comparisons were subsequently performed using Dunn's procedure (34) with Bonferroni correction for multiple comparisons and statistical significance accepted at $p<0.0017$.

\section{RESULTS}

\section{Demographics}

Mean age significantly differed between-groups $(U=7,743$, $z=-2.818, p=0.01)$. Children with a vestibular disorder reported hearing difficulty significantly more frequently than healthy children $(U=8,421.5, z=-4.148, p<0.001)$. No between-group gender or binocular vision difficulty differences were noted. Demographic data are reported in Table 2.

${ }^{2} \mathrm{http}: / /$ psico.fcep.urv.es/utilitats/factor.

TABLE 2 | Participant characteristics.

\begin{tabular}{lcc}
\hline Variable & $\begin{array}{c}\text { Patient group } \\
(\boldsymbol{n}=\mathbf{1 1 4})\end{array}$ & $\begin{array}{c}\text { Healthy children } \\
(\boldsymbol{n}=\mathbf{1 6 9 )}\end{array}$ \\
\hline Age (years) (mean, range) & $12.8(6-17)$ & $11.9(6-17)^{\star}$ \\
Gender (n) & $62(54.4 \%)$ & $89(52.7 \%)$ \\
Female, $n$ (\%) & $52(45.6 \%)$ & $80(47.3 \%)$ \\
Male, $n$ (\%) & $82(71.9 \%)$ & - \\
Presence of migraine, $n$ (\%) & $23(20.5 \%)$ & $18(10.7 \%)$ \\
Binocular vision difficulty, $n$ (\%) & $2(3.5 \%)$ & $5(3.0 \%)$ \\
$\quad$ Astigmatism, $n$ (\%) & $13(11.6 \%)$ & \\
Hearing difficulty, $n$ (\%) & & \\
Diagnosis, $\mathbf{n}$ & $8(2)$ & \\
VN (+M) & $3(2)$ & \\
BVH (+SNHL) & $1(1)$ & \\
Post-traumatic secondary & & \\
hydrops (+overlap M) & $2(1)$ & \\
PVD following OM (+M) & $42(18)$ & \\
Concussion (+M) & 58 & \\
Migraine &
\end{tabular}

VN, peripheral vestibular disorder, compatible with a history of past vestibular neuritis; $M$, meets International Headache Society diagnostic criteria for migraine; BVH, bilateral vestibular hypofunction; SNHL, sensory neural hearing loss; PVD, peripheral vestibular disorder; OM, otitis media.

*Indicates a significant $p \leq 0.01$ between-group difference between healthy children vs. the patient group comprising of all children with a primary migraine, concussion, or vestibular diagnosis.

\section{Internal Consistency Reliability}

The PVID obtained a Cronbach alpha score of 0.90 . Item-deleted statistics showed no significant change in alpha scores (range $0.88-0.90$ ). All items correlated significantly with the total score; a corrected total-item correlation $\geq 0.4$ suggested each item had discriminative capacity.

\section{Factor Analysis}

The PAF's suitability to the 11 PVID items was assessed prior to analysis. The correlation matrix revealed all variables had many correlation coefficients $>0.3$ and its factorability was confirmed (Kaiser-Meyer-Olkin value $=0.9$, Bartlett's Test of Sphericity $p<0.001$ ) (35). Parallel analysis indicated a single factor structure and PAF analysis revealed one factor explaining $50.63 \%$ of the total variance. All items had a factor loading of $>0.4$ and were retained.

\section{Discriminant Validity and Comparison between Groups}

The PVID score significantly differed between the healthy and patient group $(U=2,436.5, z=-10.719, p<0.001$; Table 3$)$. ROC analysis demonstrated that the PVID could discriminate between the two groups. The optimal cut-off score was 0.45 (out of 3 ) with a sensitivity of $83 \%$ and specificity of $75 \%$. Area under the curve (with 95\% confidence intervals) was $0.87(0.83-0.96, p<0.001)$. Figure 1 shows the ROC curve with various cut-off scores for discriminating between-groups.

The only significant correlation noted was between PVID and PVSQ scores for both groups, whereby, higher scores for the former correlated with higher scores for the latter (healthy: $r=0.64$,

TABLE 3 | Mean (SD) for questionnaire scores.

\begin{tabular}{lcc}
\hline Questionnaires & $\begin{array}{c}\text { Patient group; } \\
\boldsymbol{n}=\mathbf{1 1 4}\end{array}$ & $\begin{array}{c}\text { Healthy children; } \\
\boldsymbol{n}=\mathbf{1 6 9}\end{array}$ \\
\hline PVID & $1.18(0.74)$ & $0.28(0.33)^{\star}$ \\
PVSQ & $1.35(0.59)$ & $0.33(0.31)^{\star}$ \\
SDQ informant rated, $n$ & $n=23$ & $n=45$ \\
Total score & $19.86(9.00)$ & $10.64(4.80)^{\star}$ \\
Emotional symptom score & $4.52(2.82)$ & $3.02(2.19)$ \\
Conduct problems scale & $2.81(2.40)$ & $1.87(1.10)$ \\
Hyperactivity scale & $4.52(2.00)$ & $3.44(1.98)$ \\
Peer problems score & $2.57(1.86)$ & $2.31(1.82)$ \\
Prosocial behavior score & $8.10(2.02)$ & $8.84(3.42)$ \\
SDQ self rated, $n$ & $n=91$ & $n=124$ \\
Total score & $13.38(6.55)$ & $8.89(4.60)^{\star}$ \\
Emotional symptom score & $4.26(2.64)$ & $2.07(1.63)^{\star}$ \\
Conduct problems scale & $2.59(2.14)$ & $1.81(1.38)$ \\
Hyperactivity scale & $4.62(2.36)$ & $3.21(2.15)^{\star}$ \\
Peer problems score & $1.91(1.87)$ & $1.81(1.92)$ \\
Prosocial behavior score & $7.86(1.94)$ & $7.15(2.22)$ \\
\hline
\end{tabular}

$P V I D$, pediatric visually induced dizziness questionnaire; PVSQ, pediatric vestibular symptom questionnaire; $S D Q$, strengths and difficulties questionnaire scores for the informant (children $<11$ years old) and self-rated ( $\geq 11$ years old) versions.

*Indicates a significant $p \leq 0.01$ between-group difference between healthy children vs. the patient group comprising of all children with a primary migraine, concussion, or vestibular diagnosis. 
$p<0.001$; patients: $r=0.43, p<0.001)$. No correlations were noted between PVID scores and either age, hearing, or binocular vision function in either group.

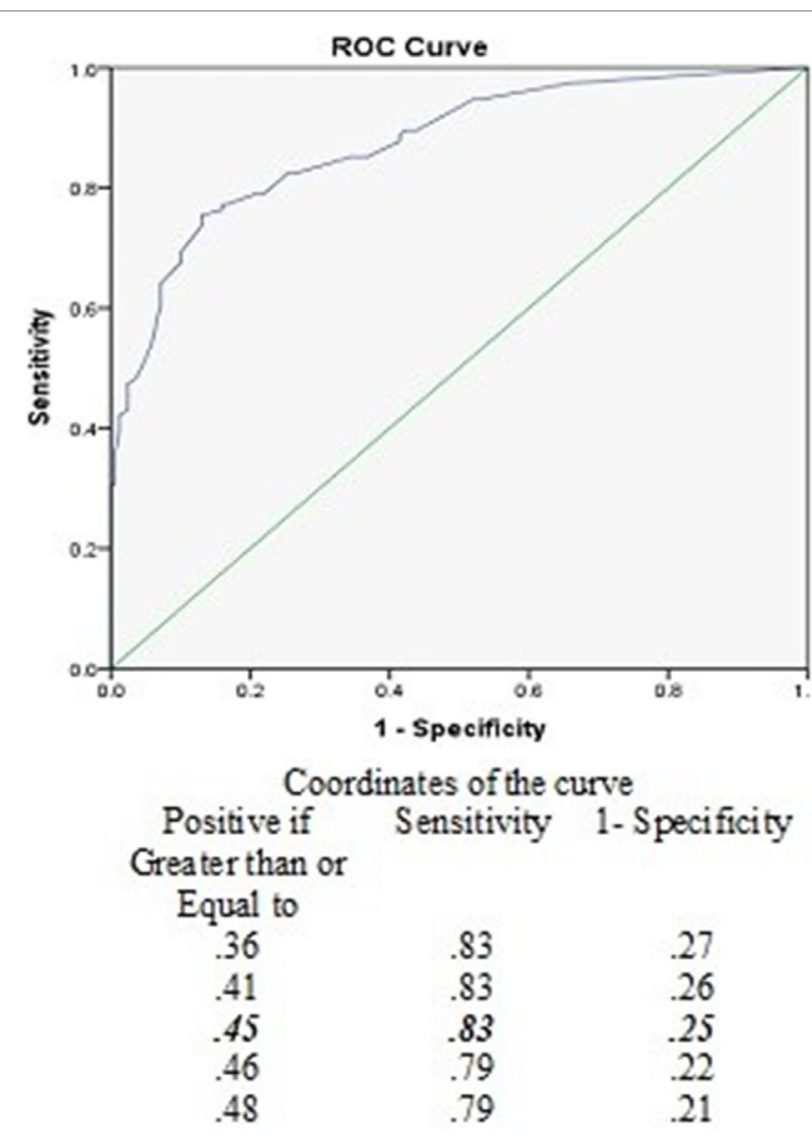

FIGURE 1 | Receiver operating curves (ROC) for various cut-off levels of the pediatric visually induced dizziness questionnaire to discriminate between healthy children and the patient group.

\section{PVID and PVSQ Scores between Patient Groups}

A significant between-group difference was noted for each individual patient group vs. the healthy group (vestibular: $U=57$, $z=-6.016, p<0.001$; concussion: $U=748.5, z=-8.004$, $p<0.001$; migraine: $U=1,631, z=-7.657, p<0.001)$. As PVID score distribution was not similar for all individual patient groups, as assessed by visual inspection of a boxplot, the mean rank was used for Kruskal-Wallis analysis. Mean rank PVID scores significantly differed between patient groups $\left[\chi^{2}(2)=11.014\right.$; $p=0.004$ ], whereby scores increased from a primary migraine (mean rank $=49.92$ ) to concussion (mean rank $=59.76$ ) to vestibular (mean rank = 82.11) diagnosis. However, post hoc analysis showed no significant pairwise comparisons. PVID scores were abnormal for 100,88 , and $72 \%$ of children with a primary vestibular, concussion, or migraine diagnosis, respectively.

Mean number ViD triggers per person were 7.94 (SD 2.65, range 1-11), 6.77 (SD 2.90, range 0-11), 5.27 (SD 3.31, range $0-11$ ), and 2.05 (SD 2.34, range $0-10$ ) in the vestibular, concussion, migraine, and healthy groups, respectively. No triggers were reported by $2(n=1), 5(n=3)$, and $34.3 \%(n=58)$ for the concussion, migraine, and healthy groups, respectively. Percentage endorsement for each PVID item is included in Table 4.

Pediatric Vestibular Symptom Questionnaire score distribution was similar across patient groups. Median PVSQ scores showed no significant differences between patient groups. 100, 97.6, and $86.2 \%$ of children with a primary vestibular, concussion, or migraine diagnosis, respectively, had abnormal PVSQ scores (13).

\section{Strength and Difficulties Questionnaire}

Significant between-group differences were noted for the selfrated SDQ with significantly higher scores for the patient vs. healthy group for the emotional $(U=2,730.0, z=-6.169$, $p<0.001)$, and hyperactivity $(U=3,445.0, z=-4.506, p<0.001)$ subscales and total score $(U=3,178.5, z=-5.083, p<0.001)$. Informant-rated SDQ scores showed a significant between-group

TABLE 4 | Percentage endorsement for each Pediatric Visually Induced Dizziness Questionnaire (PVID) item for the healthy and individual patient groups based on primary diagnosis.

Endorsement for each item (\%)

\section{PVID item}

Riding in a car

Walking down a supermarket aisle or in a busy shop

Standing in the middle of a wide open space

Watching T.V. or at the cinema

Riding on a bus

Looking at striped or moving surface

Using the computer

Watching moving traffic or trains

Playing in the playground

Doing schoolwork

Participating in sports

\begin{tabular}{cccc}
\hline Healthy $(\boldsymbol{n}=\mathbf{1 6 9})$ & Migraine $(\boldsymbol{n}=\mathbf{5 8})$ & Concussion $(\boldsymbol{n}=\mathbf{4 2})$ & Vestibular $(\boldsymbol{n}=\mathbf{1 4})$ \\
\hline $\mathbf{3 9 . 9}$ & $\mathbf{6 0 . 3}$ & 68.3 & 71.4 \\
7.7 & 46.6 & 61.0 & 76.9 \\
8.9 & 43.1 & 32.5 & 71.4 \\
14.8 & 51.7 & 66.7 & $\mathbf{8 5 . 7}$ \\
17.4 & 44.8 & 62.5 & 72.7 \\
22.6 & $\mathbf{6 0 . 3}$ & 63.4 & $\mathbf{8 5 . 7}$ \\
$\mathbf{3 0 . 2}$ & $\mathbf{6 2 . 1}$ & $\mathbf{7 3 . 8}$ & 71.4 \\
17.8 & 50.0 & 65.9 & $\mathbf{8 5 . 7}$ \\
14.9 & 41.4 & 37.5 & $\mathbf{8 5 . 7}$ \\
$\mathbf{2 3 . 2}$ & $\mathbf{6 5 . 5}$ & $\mathbf{8 4 . 6}$ & 78.6 \\
14.9 & 56.9 & $\mathbf{8 3 . 9}$ & $\mathbf{9 2 . 1}$
\end{tabular}

The three highest endorsement item percentages for each group are in bold. Columns with $>3$ items endorsed indicate equal endorsement of certain items. 
difference for the total score only $(U=188.5, z=-3.916$, $p<0.001)$. Mean self- and informant-rated SDQ scores were within normal ranges for healthy children, as expected based on exclusion criteria, and for older children in the patient group (age $\geq 11$ years old, completed self-rated SDQ), who were not excluded if they had borderline $(n=11)$ or abnormal scores $(n=8)$ (Table 3$)$. For younger children in the patient group (informant-rated SDQs), mean total and emotional subscale scores were abnormal, conduct, and peer problem scores borderline while hyperactivity and prosocial behavior scores were within normal ranges $(29,36)$.

In the healthy group, a significant relationship was noted between mean self-rated SDQ emotional and both PVID $(r=0.30, p<0.001)$ and PVSQ $(r=0.24, p=0.007)$ scores and between the PVSQ with both hyperactivity $(r=0.27, p=0.002)$ and total SDQ $(r=0.25, p=0.006)$ scores, whereby higher SDQ scores correlated with higher questionnaire scores. In the patient group, no significant correlations were noted for the self-rated SDQ; however, for informant-rated SDQs, a significant relationship was noted between total and emotional subscale scores with PVID (total: $r=0.65, p=0.001$; emotional: $r=0.69, p=0.001$ ), PVSQ (total: $r=0.60, p=0.004$; emotional: $r=0.55, p=0.01$ ), and migraine (total: $r=0.74, p=0.01$; emotional: $r=0.55$, $p=0.01$ ), whereby higher SDQ scores were associated with higher questionnaire scores and migraine history.

\section{DISCUSSION}

This is the first study to provide evidence that ViD exists in childhood, with significant differences noted between the healthy and patient group for $\mathrm{ViD}$ symptom severity, number of PVID items endorsed, and SDQ scores. The number of children reporting visual environmental triggers, mean number of items endorsed by each child in the patient groups, and percentage endorsement for each item is significantly greater than that noted in adults with a vestibular disorder (37). These findings may partly be due to the types of environmental triggers included in each scale, but are mostly likely explained by factors specific to children including immaturity in motion processing systems (38) and a prolonged time course for development of the ability to integrate multisensory cues to resolve sensory conflicting situations (23), with increased reliance on visual cues for spatial orientation (22). Children show less selective or robust responses to optic flows differing in pattern or speed, and motion processing networks continue to experience "fine-tuning" throughout the transition to adulthood (38). It is interesting thus to note that "standing in a wide-open space" is one of the items least endorsed for children with concussion and/or migraine, suggesting less susceptibility to environments with insufficient visual information and greater susceptibility to visual information overload (striped/moving surfaces, doing schoolwork, i.e., flickering effect when eye movements pass over print, sports, e.g., number and tracking of team players).

Children with a vestibular disorder endorsed all PVID items highly. The main triggers endorsed by children with concussion and/or migraine were also diverse, with computer use and doing schoolwork identified as key triggers. Recent studies have indicated an association between increased screen time, headache frequency (39), dizziness symptoms $(39,40)$, and psychological distress (41) in children. Time spent on smartphones, tablets, and computers should be considered when asking children about their symptoms and symptom triggers.

Visually induced dizziness is believed to be due to visual dependency (42) and is supported by studies showing increased visual cortical excitability in persons with vestibular dysfunction (43) and migraineurs (44). Similarly, in persons with concussion, an increased coherent motion threshold has been noted, indicating damage to the magnocellular pathway, which is directly involved in visual motion processing (45). The detection of coherent motion is required to be able to detect the correct direction of movement. Therefore, it follows that an increase threshold indicates increase visual motion sensitivity. These findings are consistent with visual motion sensitivity and vertigo symptoms reported by persons with concussion in their natural environments (45).

The relationship between motion sickness and increased visual dependence also exists with a stronger influence of disorienting visual stimuli on verticality perception (46) and an inability to accurately use available visual input to resolve conflicting sensory information (47). The most common symptom triggers in healthy children were those specifically relating to motion sickness, including computer use, with the percentage similar to that noted in previous work (48). All healthy individuals may become motion sick, but individual susceptibility varies widely and is primarily due to genetic hereditability (49) and gender, with girls more susceptible than boys (48). No age or gender effect was noted on PVID scores for any group. This may be because correlation analysis assessed the relationship between mean PVID scores with age and gender, rather than individual items relating to motion sickness.

No relationship was noted between the presence of a binocular visual abnormality and PVID scores. This finding is in agreement with adult data showing no difference in baseline ViD scores between persons with a vestibular disorder with and without binocular vision abnormalities (50). This does not exclude though a potential contribution of the visual system to the presence of these symptoms, although the term ViD specifically refers to the environmental triggers of these symptoms.

Children with a primary migraine diagnosis had been diagnosed by their primary care physician. An abnormal PVSQ score was noted in $86.2 \%$, indicating increased vestibular symptoms, while PVID scores were abnormal for $72 \%$ with $95 \%$ endorsing at least one symptom trigger. Vestibular symptoms of dizziness and ViD may indicate vestibular migraine (20), which may occur at any age and is widely underdiagnosed $(51,52)$. In one study, vestibular migraine accounted for $20.2 \%$ of the diagnoses, but was suspected by the referring health-care professional in only $1.8 \%$ (53). Dizziness/vertigo are common symptoms in children with migraine (54) and require a comprehensive neuro-otological assessment for correct diagnosis and exclusion of other diagnoses that may cause these symptoms (20). However, none of the children in the migraine group had been referred for a neurootological assessment.

Children with concussion, migraine, and/or vestibular disorder should also be screened for associated psychological 
symptoms, perceived handicap, and QOL (55-58). Mean SDQ scores were increased compared to healthy controls for both self- and informant-rated versions. Significant correlations were noted between questionnaires, migraine history, and SDQ for the informant-rated version in patients, consistent with adult studies $(59,60)$, indicating a contributory role of the limbic system for these symptoms (61). Parent SDQ reports are more discriminating than youth self-reports (62), thus these findings may more accurately represent the true associations between these measures compared to self-report data.

Increased sensitivity to visual motion stimuli has been reported in persons with persistent postural-perceptual dizziness (PPPD), functional dizziness, and chronic subjective dizziness (CSD) (63-65). Children with a vestibular disorder or concussion had not received any of these diagnoses, and there are no studies to our knowledge that have evaluated the presence of these conditions in a pediatric population. It is unknown if any children in the migraine group may have been provided with an additional diagnosis of PPPD, CSD, or functional dizziness if they had received a full neuro-otological assessment. However, our data show that increased $\mathrm{ViD}$ symptoms are common in children with a vestibular disorder, migraine, and/or concussion, and it has been argued that persons with ViD should receive specific rehabilitation regardless of what gives rise to this symptoms' constellation (21).

Greater difficulties at school and decreased academic performance are reported for children with concussion or migraine, with contributing factors including headache severity and impact, work accumulation from missing school, potential stress associated with this, and cognitive effects particularly following concussion $(57,66)$. Our data suggest that increased ViD symptoms may also be a contributing factor to decreased school functioning and should be considered.

A significant relationship was also noted between PVID, PVSQ, and self-rated SDQ scores in healthy participants. In healthy adolescents, a significant correlation exists between subjective health complaints (i.e., dizziness, fatigue), focusing on re-occurring symptom frequency rather than diagnoses, and higher SDQ scores, indicating greater emotional/behavioral problems (67). We hypothesize that in, healthy participants, the relationship between PVSQ, PVID, and SDQ scores may result from the presence of subjective health complaints in a percentage of participants.

The PVID provides a valid tool that may reliably identify ViD. A ROC area under the curve indicates a test with "good accuracy" in separating those with and without abnormal ViD symptom levels (68). Construct validity was shown by factor analysis, which retained all items organized into one dimension (i.e., single factor structure) representing ViD symptoms. Using two rules to determine the number of dimensions in the data adds robustness to the decision and subsequent data interpretation (69). In the current study, the Kaiser criteria and scree plot were supplemented by a parallel analysis with minimum rank factor analysis. Parallel analysis, which also extracted one dimension, is the only approach that formally tests the probability that a factor is due to chance and allows for a high degree of confidence regarding the number of factors to extract (70).
Cronbach's alpha above the recommended values of 0.8 (71) or 0.7 for a new instrument $(72,73)$ indicated high internal consistency and $a \geq 0.4$ correlation for all items with the total score also suggested that all items contribute to the PVID's reliability. The PVID may thus be a clinically valuable tool to assess children with dizziness-related symptoms to inform diagnosis and appropriate management.

Some study limitations were present. No neuro-otological assessment was completed for children with a primary migraine diagnosis as they were recruited from mainstream schools and no information was collected about migraine characteristics, academic performance, and QOL, which may have provided greater insight into the relationships between these factors and ViD. The absence of data regarding wearing glasses and further details of squints and stereoscopy is also a study limitation. Further research on test-retest reliability and responsiveness to change over time is needed to further validate the PVID for clinical use. Currently, the questionnaire is not validated for children with learning disabilities, as questionnaires should be specifically adapted for populations experiencing reading and comprehension difficulties (74). This should be considered particularly when used in children with concussion who may experience cognitive deficits (75).

\section{Conclusion}

Increased $\mathrm{ViD}$ symptoms are present in children with migraine, concussion, and/or vestibular disorders. Increased knowledge translation is required so that health-care professionals are aware of these symptoms and how to identify them. The PVID is a reliable and valid measure for assessing $\mathrm{ViD}$ presence and severity in children. A better understanding of the relationships between symptoms, symptom triggers, functional domains, and QOL may improve the management approach and outcome for these children.

\section{ETHICS STATEMENT}

This study was carried out in accordance with the recommendations of the Institute of Child Health/GOSH Research Ethics Committee, London, UK and the institutional review board at the University of Pittsburgh, PA, USA. Ethical approval was obtained from the Institute of Child Health/GOSH Research Ethics Committee, London, UK and the institutional review board at the University of Pittsburgh, PA, USA. Written informed consent was obtained from all children and their parents before participating in the study in accordance with the Declaration of Helsinki.

\section{AUTHOR CONTRIBUTIONS}

MP conceptualized and designed the study, contributed to the design of the data collection instrument, collected data for children with vestibular disorders from GOSH, London, UK, contributed to data analyses, drafted the initial manuscript, and approved the final manuscript as submitted. SW contributed to the design of the data collection instrument, coordinated and supervised data collection at UPMC, Pittsburgh, PA, USA, 
critically reviewed and revised the manuscript, and approved the final manuscript as submitted. AA was involved in data collection at UPMC and carried out the initial analyses. $\mathrm{MH}$ coordinated and supervised data collection at all five sites for the healthy control group, critically reviewed and revised the manuscript, and approved the final manuscript as submitted. EG contributed to the study design, critically reviewed and revised the manuscript, and approved the final manuscript as submitted. LL, ER, and DEB contributed to the design of the data collection instrument, recruited children with vestibular disorders from GOSH, critically reviewed and revised the manuscript and approved the final manuscript as submitted. DEB also contributed to data analyses.

\section{REFERENCES}

1. Balatsouras DG, Kaberos A, Assimakopoulos D, Katotomichelakis M, Economou NC, Korres SG. Etiology of vertigo in children. Int J Pediatr Otorhinolaryngol (2007) 71(3):487-94. doi:10.1016/j.ijporl.2006.11.024

2. Physicians RCo. Hearing and Balance Disorders: Achieving Excellence in Diagnosis and Management. Report of a Working Party. London: RCP (2008).

3. Humphriss R, Hall A, May M, Macleod J. Balance ability of 7 and 10 year old children in the population: results from a large UK birth cohort study. Int J Pediatr Otorhinolaryngol (2011) 75(1):106-13. doi:10.1016/j. ijporl.2010.10.019

4. Jahn K. Vertigo and dizziness in children. Handb Clin Neurol (2016) 137:353-63. doi:10.1016/B978-0-444-63437-5.00025-X

5. Jahn K, Langhagen T, Heinen F. Vertigo and dizziness in children. Curr Opin Neurol (2015) 28(1):78-82. doi:10.1097/WCO.0000000000000157

6. Li CM, Hoffman HJ, Ward BK, Cohen HS, Rine RM. Epidemiology of dizziness and balance problems in children in the United States: a populationbased study. J Pediatr (2016) 171:240-7.e241-3. doi:10.1016/j.jpeds.2015. 12.002

7. Lau BC, Kontos AP, Collins MW, Mucha A, Lovell MR. Which on-field signs/symptoms predict protracted recovery from sport-related concussion among high school football players? Am J Sports Med (2011) 39(11):2311-8. doi:10.1177/0363546511410655

8. Wiener-Vacher SR. Vestibular disorders in children. Int J Audiol (2008) 47(9):578-83. doi:10.1080/14992020802334358

9. Sommerfleck PA, González Macchi ME, Weinschelbaum R, De Bagge MD, Bernáldez P, Carmona S. Balance disorders in childhood: main etiologies according to age. Usefulness of the video head impulse test. Int J Pediatr Otorhinolaryngol (2016) 87:148-53. doi:10.1016/j.ijporl.2016.06.020

10. Brodsky JR, Cusick BA, Zhou G. Vestibular neuritis in children and adolescents: clinical features and recovery. Int J Pediatr Otorhinolaryngol (2016) 83:104-8. doi:10.1016/j.ijporl.2016.01.027

11. Casselbrant ML, Mandel EM. Balance disorders in children. Neurol Clin (2005) 23(3):807-29, vii. doi:10.1016/j.ncl.2005.03.003

12. Rine RM, Wiener-Vacher S. Evaluation and treatment of vestibular dysfunction in children. NeuroRehabilitation (2013) 32(3):507-18. doi:10.3233/ NRE-130873

13. Pavlou M, Whitney S, Alkathiry AA, Huett M, Luxon LM, Raglan E, et al. The pediatric vestibular symptom questionnaire: a validation study. J Pediatr (2016) 168:171-7.e171. doi:10.1016/j.jpeds.2015.09.075

14. McCaslin DL, Jacobson GP, Lambert W, English LN, Kemph AJ. The development of the vanderbilt pediatric dizziness handicap inventory for patient caregivers (DHI-PC). Int J Pediatr Otorhinolaryngol (2015) 79(10):1662-6. doi:10.1016/j.ijporl.2015.07.017

15. Brodsky JR, Cusick BA, Zhou G. Evaluation and management of vestibular migraine in children: experience from a pediatric vestibular clinic. Eur J Paediatr Neurol (2016) 20(1):85-92. doi:10.1016/j.ejpn.2015.09.011

16. Hall CD, Herdman SJ, Whitney SL, Cass SP, Clendaniel RA, Fife TD, et al. Vestibular rehabilitation for peripheral vestibular hypofunction: an evidencebased clinical practice guideline: from the American physical therapy association neurology section. J Neurol Phys Ther (2016) 40(2):124-55. doi:10.1097/ NPT.0000000000000120

\section{ACKNOWLEDGMENTS}

We would like to thank Dr. Victoria Cornelius, Senior Lecturer in Medical Statistics and Clinical Trials, Imperial College London, and Joint Academic Lead for the Research Design Service for West London, for her review of the statistical analysis and results.

\section{FUNDING}

MP wrote the first draft of the manuscript. No honorarium, grant, or other form of payment was given to anyone to produce the manuscript. Open access for this article was funded by King's College London.

17. Bisdorff A, Von Brevern M, Lempert T, Newman-Toker DE. Classification of vestibular symptoms: towards an international classification of vestibular disorders. J Vestib Res (2009) 19(1-2):1-13. doi:10.3233/VES2009-0343

18. Guerraz M, Yardley L, Bertholon P, Pollak L, Rudge P, Gresty MA, et al. Visual vertigo: symptom assessment, spatial orientation and postural control. Brain (2001) 124(Pt 8):1646-56. doi:10.1093/brain/124.8.1646

19. Cousins S, Cutfield NJ, Kaski D, Palla A, Seemungal BM, Golding JF, et al. Visual dependency and dizziness after vestibular neuritis. PLoS One (2014) 9(9):e105426. doi:10.1371/journal.pone.0105426

20. Lempert T. Vestibular migraine. Semin Neurol (2013) 33(3):212-8 doi:10.1055/s-0033-1354596

21. Bronstein AM. Multisensory integration in balance control. Handb Clin Neurol (2016) 137:57-66. doi:10.1016/B978-0-444-63437-5.00004-2

22. Bagust J, Docherty S, Haynes W, Telford R, Isableu B. Changes in rod and frame test scores recorded in schoolchildren during development a longitudinal study. PLoS One (2013) 8(5):e65321. doi:10.1371/journal. pone.0065321

23. Steindl R, Kunz K, Schrott-Fischer A, Scholtz AW. Effect of age and sex on maturation of sensory systems and balance control. Dev Med Child Neurol (2006) 48(6):477-82. doi:10.1111/j.1469-8749.2006.tb01299.x

24. Pavlou M, Lingeswaran A, Davies RA, Gresty MA, Bronstein AM. Simulator based rehabilitation in refractory dizziness. J Neurol (2004) 251(8):983-95. doi:10.1007/s00415-004-0476-2

25. Pavlou M, Kanegaonkar RG, Swapp D, Bamiou DE, Slater M, Luxon LM The effect of virtual reality on visual vertigo symptoms in patients with peripheral vestibular dysfunction: a pilot study. J Vestib Res (2012) 22(5-6): 273-81. doi:10.3233/VES-120462

26. Bell A. Designing and testing questionnaires for children. J Res Nurs (2007) 12:461-9. doi:10.1177/1744987107079616

27. Jackson CFA. Designing and Analysing Questionnaires and Surveys: A Manual for Health Professionals and Administrators. London: Whurr (2000).

28. Jacob RG, Lilienfeld SO, Furman JMR, Durrant JD, Turner SM. Panic disorder with vestibular dysfunction: further clinical observations and description of space and motion phobi stimuli. J Anxiety Disord (1989) 3: 117-30. doi:10.1016/0887-6185(89)90006-6

29. Goodman R. The strengths and difficulties questionnaire: a research note. J Child Psychol Psychiatry (1997) 38(5):581-6. doi:10.1111/j.1469-7610.1997. tb01545.x

30. Goodman R, Meltzer H, Bailey V. The strengths and difficulties questionnaire: a pilot study on the validity of the self-report version. Eur Child Adolesc Psychiatry (1998) 7(3):125-30. doi:10.1007/s007870050057

31. Bryman A, Cramer D. Quantitative Data Analysis with SPSS Release 8 for Windows. A Guide for Social Scientists. London: Routledge (1999).

32. Timmerman ME, Lorenzo-Seva U. Dimensionality assessment of ordered polytomous items with parallel analysis. Psychol Methods (2011) 16(2):209-20. doi:10.1037/a0023353

33. Lorenzo-Seva U, Ferrando PJ. FACTOR: a computer program to fit the exploratory factor analysis model. Behav Res Methods (2006) 38(1):88-91. doi:10.3758/BF03192753

34. OJ D. Multiple comparisons using rank sums. Technometrics (1964) 6:241-52. doi:10.1080/00401706.1964.10490181 
35. Kaiser HF. An index of factorial simplicity. Psychometrika (1974) 39:31-6. doi:10.1007/BF02291575

36. Bourdon KH, Goodman R, Rae DS, Simpson G, Koretz DS. The strengths and difficulties questionnaire: U.S. normative data and psychometric properties. J Am Acad Child Adolesc Psychiatry (2005) 44(6):557-64. doi:10.1097/ 01.chi.0000159157.57075.c8

37. Whitney SL, Alghadir A, Alghwiri A, Alshebber KM, Alshehri M, Furman JM, et al. The development of the ICF vestibular environmental scale. J Vestib Res (2016) 26(3):297-302. doi:10.3233/VES-160580

38. Gilmore RO, Thomas AL, Fesi J. Children's brain responses to optic flow vary by pattern type and motion speed. PLoS One (2016) 11(6):e0157911. doi:10.1371/journal.pone.0157911

39. Torsheim T, Eriksson L, Schnohr CW, Hansen F, Bjarnason T, Välimaa R. Screenbased activities and physical complaints among adolescents from the Nordic countries. BMC Public Health (2010) 10:324. doi:10.1186/1471-2458-10-324

40. Taehtinen RE, Sigfusdottir ID, Helgason AR, Kristjansson AL. Electronic screen use and selected somatic symptoms in 10-12 year old children. Prev Med (2014) 67:128-33. doi:10.1016/j.ypmed.2014.07.017

41. Kleppang AL, Thurston M, Hartz I, Hagquist C. Psychological distress among Norwegian adolescents: changes between 2001 and 2009 and associations with leisure time physical activity and screen-based sedentary behaviour. Scand J Public Health (2017). doi:10.1177/1403494817716374

42. Bronstein AM. The visual vertigo syndrome. Acta Otolaryngol Suppl (1995) 520(Pt 1):45-8. doi:10.3109/00016489509125186

43. Dieterich M, Bauermann T, Best C, Stoeter P, Schlindwein P. Evidence for cortical visual substitution of chronic bilateral vestibular failure (an fMRI study). Brain (2007) 130(Pt 8):2108-16. doi:10.1093/brain/awm130

44. Aurora SK, Wilkinson F. The brain is hyperexcitable in migraine. Cephalalgia (2007) 27(12):1442-53. doi:10.1111/j.1468-2982.2007.01502.x

45. Patel R, Ciuffreda KJ, Tannen B, Kapoor N. Elevated coherent motion thresholds in mild traumatic brain injury. Optometry (2011) 82(5):284-9. doi:10.1016/j.optm.2010.10.012

46. Yardley L. Motion sickness susceptibility and the utilisation of visual and otolithic information for orientation. Eur Arch Otorhinolaryngol (1990) 247(5):300-4. doi:10.1007/BF00176542

47. Bijveld MM, Bronstein AM, Golding JF, Gresty MA. Nauseogenicity of off-vertical axis rotation vs. equivalent visual motion. Aviat Space Environ Med (2008) 79(7):661-5. doi:10.3357/ASEM.2241.2008

48. Henriques IF, Douglas de Oliveira DW, Oliveira-Ferreira F, Andrade PM. Motion sickness prevalence in school children. Eur J Pediatr (2014) 173(11): 1473-82. doi:10.1007/s00431-014-2351-1

49. Reavley CM, Golding JF, Cherkas LF, Spector TD, MacGregor AJ. Genetic influences on motion sickness susceptibility in adult women: a classical twin study. Aviat Space Environ Med (2006) 77(11):1148-52.

50. Pavlou M, Acheson J, Nicolaou D, Fraser CL, Bronstein AM, Davies RA. Effect of developmental binocular vision abnormalities on visual vertigo symptoms and treatment outcome. J Neurol Phys Ther (2015) 39(4):215-24. doi:10.1097/NPT.0000000000000105

51. Cass SP, Furman JM, Ankerstjerne K, Balaban C, Yetiser S, Aydogan B. Migraine-related vestibulopathy. Ann Otol Rhinol Laryngol (1997) 106(3):182-9. doi:10.1177/000348949710600302

52. Lempert T, Olesen J, Furman J, Waterston J, Seemungal B, Carey J, et al. [Vestibular migraine: diagnostic criteria: consensus document of the Barany Society and the International Headache Society]. Nervenarzt (2013) 84(4):511-6. doi:10.1007/s00115-013-3768-x

53. Geser R, Straumann D. Referral and final diagnoses of patients assessed in an academic vertigo center. Front Neurol (2012) 3:169. doi:10.3389/fneur.2012.00169

54. Raucci U, Vanacore N, Paolino MC, Silenzi R, Mariani R, Urbano A, et al. Vertigo/dizziness in pediatric emergency department: five years' experience. Cephalalgia (2016) 36(6):593-8. doi:10.1177/0333102415606078

55. Reale L, Guarnera M, Grillo C, Maiolino L, Ruta L, Mazzone L. Psychological assessment in children and adolescents with benign paroxysmal vertigo. Brain $\operatorname{Dev}(2011)$ 33(2):125-30. doi:10.1016/j.braindev.2010.03.006

56. Lee CH, Lee SB, Kim YJ, Kong WK, Kim HM. Utility of psychological screening for the diagnosis of pediatric episodic vertigo. Otol Neurotol (2014) 35(10):e324-30. doi:10.1097/MAO.0000000000000559

57. Novak Z, Aglipay M, Barrowman N, Yeates KO, Beauchamp MH, Gravel J, et al. Association of persistent postconcussion symptoms with pediatric quality of life. JAMA Pediatr (2016) 170:e162900. doi:10.1001/jamapediatrics.2016.2900
58. Öztop DB, Taşdelen Bİ, PoyrazoğLu HG, Ozsoy S, Yilmaz R, Şahın N, et al. Assessment of psychopathology and quality of life in children and adolescents with migraine. J Child Neurol (2016) 31(7):837-42. doi:10.1177/ 0883073815623635

59. Bisdorff A, Andrée C, Vaillant M, Sándor PS. Headache-associated dizziness in a headache population: prevalence and impact. Cephalalgia (2010) 30(7):815-20. doi:10.1177/0333102409353617

60. Best C, Eckhardt-Henn A, Tschan R, Dieterich M. Why do subjective vertigo and dizziness persist over one year after a vestibular vertigo syndrome? Ann N Y Acad Sci (2009) 1164:334-7. doi:10.1111/j.1749-6632.2009.03847.x

61. Maizels M, Aurora S, Heinricher M. Beyond neurovascular: migraine as a dysfunctional neurolimbic pain network. Headache (2012) 52(10):1553-65. doi:10.1111/j.1526-4610.2012.02209.x

62. Kuhn C, Aebi M, Jakobsen H, Banaschewski T, Poustka L, Grimmer Y, et al. Effective mental health screening in adolescents: should we collect data from youth, parents or both? Child Psychiatry Hum Dev (2016) 48(3):385-92. doi:10.1007/s10578-016-0665-0

63. Staab JP, Rohe DE, Eggers SD, Shepard NT. Anxious, introverted personality traits in patients with chronic subjective dizziness. J Psychosom Res (2014) 76(1):80-3. doi:10.1016/j.jpsychores.2013.11.008

64. Bittar RS, Lins EM. Clinical characteristics of patients with persistent postural-perceptual dizziness. Braz J Otorhinolaryngol (2015) 81(3):276-82 doi:10.1016/j.bjorl.2014.08.012

65. Söhsten E, Bittar RS, Staab JP. Posturographic profile of patients with persistent postural-perceptual dizziness on the sensory organization test. J Vestib Res (2016) 26(3):319-26. doi:10.3233/VES-160583

66. Rocha-Filho PA, Santos PV. Headaches, quality of life, and academic performance in schoolchildren and adolescents. Headache (2014) 54(7):1194-202. doi:10.1111/head.12394

67. Petanidou D, Giannakopoulos G, Tzavara C, Dimitrakaki C, Kolaitis G, Tountas Y. Adolescents' multiple, recurrent subjective health complaints: investigating associations with emotional/behavioural difficulties in a cross-sectional, school-based study. Child Adolesc Psychiatry Ment Health (2014) 8(1):3. doi:10.1186/1753-2000-8-3

68. Zweig MH, Campbell G. Receiver-operating characteristic (ROC) plots: a fundamental evaluation tool in clinical medicine. Clin Chem (1993) 39(4):561-77

69. Zwick RW, Velicer FW. Comparison of five rules for determining the number of components to retain. Psychol Bull (1986) 99(3):432-42. doi:10.1037/ 0033-2909.99.3.432

70. Wood ND, Akloubou Gnonhosou DC, Bowling J. Combining parallel and exploratory factor analysis in identifying relationship scales in secondary data Marriage Fam Rev (2015) 51(5):385-95. doi:10.1080/01494929.2015.1059785

71. Field A. Discovering Statistics Using SPSS. London: SAGE (2009).

72. DeVellis R. Scale Development: Theory and Applications. (Vol. 26). Newbury Park: SAGE (1991).

73. DeVon HA, Block ME, Moyle-Wright P, Ernst DM, Hayden SJ, Lazzara DJ, et al. A psychometric toolbox for testing validity and reliability. J Nurs Scholarsh (2007) 39(2):155-64. doi:10.1111/j.1547-5069.2007.00161.x

74. Nind M. Conducting Qualitative Research with People with Learning, Communication and Other Disabilities: Methodological Challenges. ESRC National Centre for Research Methods, Methods Review Paper. (2008). p. 1-24. Available from: http://eprints.ncrm.ac.uk/491/

75. Alsalaheen BA, Whitney SL, Marchetti GF, Furman JM, Kontos AP, Collins MW, et al. Relationship between cognitive assessment and balance measures in adolescents referred for vestibular physical therapy after concussion. Clin J Sport Med (2015) 26(1):46-52. doi:10.1097/JSM.0000000000000185

Conflict of Interest Statement: The authors declare that the research was conducted in the absence of any commercial or financial relationships that could be construed as a potential conflict of interest.

Copyright (C) 2017 Pavlou, Whitney, Alkathiry, Huett, Luxon, Raglan, Godfrey and Bamiou. This is an open-access article distributed under the terms of the Creative Commons Attribution License (CC BY). The use, distribution or reproduction in other forums is permitted, provided the original author(s) or licensor are credited and that the original publication in this journal is cited, in accordance with accepted academic practice. No use, distribution or reproduction is permitted which does not comply with these terms. 